\title{
A pilot study to determine the short-term effects of milk with differing glycaemic properties on sleep among toddlers: a randomised controlled trial
}

Snigdha Misra ${ }^{1 *}$, Geok L Khor ${ }^{1}$, Peter Mitchell ${ }^{2}$, Samsul Haque ${ }^{3}$ and David Benton ${ }^{4}$

\begin{abstract}
Background: Sleep is important for children as it directly impacts their mental and physical development. Sleep is not only influenced by the timing but also the macronutrient (carbohydrate and protein) content of meals. Glycaemic index (Gl) and glycaemic load (GL) describe the quality of carbohydrates in a food and the burden of these foods on the body's blood glucose response. Diets with a high $\mathrm{Gl} / \mathrm{GL}$ may increase the risk of developing obesity and type 2 diabetes mellitus in adulthood. The present study is piloted to evaluate the short-term impact of milk products with differing glycaemic properties on the sleep patterns of toddlers.

Methods: Toddlers were recruited from various day care centres. Informed consent was obtained from both the mothers and the centres. A double-blind randomised controlled trial with a between-subjects design was adopted. The toddlers were randomised to either one of two types of milk with a differing Gl ("Low" = 23 and "High =65") for a period of 3.5 days. There were no other dietary restrictions imposed except that the enrolled child did not consume any other milk during the study period. The sleep patterns were recorded using a Phillips Actiwatch-2, which was worn on the wrist for $24 \mathrm{~h}$ over 4 days. The parameters used to measure the sleep pattern were sleep-onset latency (SOL), total sleep time (TST), wake after sleep onset (WASO) and sleep efficiency (SE).
\end{abstract}

Results: A total of 56 toddlers completed the study. The toddlers had a mean age of $19.9 \pm 4.3$ months. There were no significant differences ( $p>0.05$ ) between the two GI groups for SOL, TST, WASO and SE at the end of the feeding period.

Conclusions: Sleep patterns of toddlers on low-Gl milk did not differ from those with high-Gl milk consumed over a short period. Future studies should consider the glycaemic effects of other foods, along with milk with differing $\mathrm{Gl}$, consumed for a longer feeding duration.

Trial registration: ClinicalTrial.gov NCT01589003.

Keywords: Glycaemic index, Toddlers, Sleep, Milk

\section{Background}

Sleep is important for children as it directly impacts their mental and physical development. During infancy, humans spend a majority of their time in sleep [1-4]. Sleep is recognised not only as a resting state, but also as a state of intense brain development during which

\footnotetext{
*Correspondence: snigdha_misra@imu.edu.my

'Division of Nutrition and Dietetics, International Medical University, 57000 Kuala Lumpur, Malaysia

Full list of author information is available at the end of the article
}

neurotransmitters specific for each sleep stage impact brain maturation $[2,5,6]$. During early years of life, it is the primary activity of the brain. Sleep problems during childhood can predict emotional and behavioural problems, as well as poor cognitive function, which may persist into later childhood and adolescence [7]. Several hormones are involved in sleep and circadian rhythmicity [8]. Growth hormone levels are increased during sleep and peak immediately subsequent to sleep onset $[9,10]$. Growth hormone is intermittently secreted 
during sleep, which could relate to the cyclic nature of slow-wave sleep [11].

Food and drinks have a major impact on sleep, and may stimulate or deter sleep. Sleep is not only influenced by the timing $[7,12]$ but also the macronutrient content $[13,14]$ of meals. A meal consumed close to bedtime is associated with sleep disturbance [7]. Macronutrients (carbohydrates and proteins) influence sleep through tryptophan (Trp). Trp serves as a precursor in the brain for serotonin. Serotonin is a neurotransmitter in the brain that acts as a sleep-inducing agent $[15,16]$. Glucose activates serotonin, which in turn regulates stress adaptation and performance $[16,17]$. Serotonin plays an important role in sleep, mood, appetite, temperature regulation and pain perception [15]. Carbohydrates $(\mathrm{CHO})$ are found to increase the plasma concentration of Trp to that of the sum of the other large neutral amino acids (LNAAs), giving Trp a competitive advantage in gaining access into the brain $[16,17]$.

Glycaemic index (GI) and glycaemic load (GL) describe the quality of $\mathrm{CHO}$ in a food and the burden of these foods on the body's blood glucose response. Diets with a high GI/GL may increase the risk of developing obesity and type 2 diabetes mellitus in adulthood $[18,19]$. High-GI (HGI) CHO have the ability to increase the ratio of circulating Trp to LNAAs (Trp:LNAA) via a direct action of insulin, which promotes the selective muscle uptake of LNAAs [20]. Thus, a HGI meal would be expected to promote sleep via an increase in brain $\operatorname{Trp}$ and serotonin as the plasma Trp:LNAA increases [21].

Milk is a staple food, especially for children, as it delivers high-quality protein and essential nutrients such as calcium, riboflavin, vitamin A and zinc. Increasingly, milk is used as a delivery vehicle for other nutrients such as docosahexaenoic acid (DHA), vitamin D and iron. In Asian countries, a new category of high-value milk products for children, growing up milk (GUM), is well established. These products are used to supplement children's diets to gain adequate nutrients. However, there is also a trend by manufacturers to increase the added sugar content of these products using a range of ingredients including sucrose, maltodextrins and corn or glucose syrups. Some of these ingredients may be useful in small amounts for increasing the palatability of the milks to encourage consumption. However, high levels of these ingredients not only dilute the nutritional value of the milk, but also increase intakes of added sugars by children. With the global trend of increasing overweight and obesity among children [22], these empty calories may be potentially harmful.

In Malaysia, children aged 1-3 years on average consumed almost $700 \mathrm{~mL}$ or 3.5 cups of milk a day, which exceeds the recommended $2-3$ cups a day $(200 \mathrm{~mL} / \mathrm{cup})$ by the Malaysian Ministry of Health (MOH) [23]. Countries around the world recommend the equivalent of 1-2 cups a day with the exception of Singapore, which recommends $750 \mathrm{~mL}$ or 3.5 cups a day for children ages 1-2 years [24]. Hence, there is a concern of added sugar in GUM contributing to HGI. A recent study found that some GUM in Malaysia and Indonesia with added $\mathrm{CHO}$ have HGI and GL scores that are up to 7 times higher than GUM with no added sugar [25]. GI and GL are linked to obesity risk and type 2 diabetes mellitus [26].

In Malaysia, the highest percentage (90.6\%) of milk drinkers was among those aged 1-3 years [24]. Malaysian children aged 1-3 years daily consumed milk that exceeded the amounts recommended by the $\mathrm{MOH}$ [23]. Both epidemiologic and methodological studies indicate a relationship between sleep and health [27, 28]. However, little is known about the impact of diet and nutrients on sleep [29-33]. Dietary CHO contain a large variety of sugar chains with differing metabolisms. Hence, it is not surprising that the amount of any individual $\mathrm{CHO}$ has no consistent influence on sleep parameters [34]. A crosssectional study of toddlers showed that the consumption of foods with HGI was accompanied by longer sleep time (1.3 $\mathrm{min} / \mathrm{g})$, whereby the children's diet was mostly based on family foods and sleep rhythmicity had been established [35]. The influence of energy and macronutrients on sleep clinical interventions confirms the cross-sectional observations that there is some relationship between the intake of macronutrients and sleep. However, the number of studies is small and substantial differences in study designs and methods exist. Additionally, none of the studies have examined the relationship between $\mathrm{CHO}$ with differing GI and the sleep characteristics among toddlers.

The purpose of this pilot study was to examine the short-term impact of low-GI (LGI) and HGI fortified milk powders on sleep characteristics among toddlers. It was hypothesised that LGI-fed toddlers would demonstrate on actigraphy a reduced total sleep time (TST), decreased sleep-onset latency (SOL), decreased waking after sleep onset (WASO) and decreased sleep efficiency (SE) as compared with the HGI group.

\section{Methods}

\section{Ethics}

The study protocol was approved by the Joint Ethics and Research Committee, International Medical University, Malaysia, with the Project Identification number IMU $\mathrm{R}$ 075/2011. The study was registered with ClinicalTrial.gov bearing identifier NCT01589003. Information about the objectives and principles of the study was given to participants. Written consent was also obtained from the parents for their toddlers to be recruited for the study.

\section{Study design}

A double-blind randomised controlled trial (between subjects) design was adopted. The enrolled toddlers were 
randomised into two groups matched for age. The study milk products were commercially available in the market and had been tested for glycaemic properties (LGI and HGI). Both of these products have passed through appropriate quality assurance procedures and are safe for consumption. The test products were coded by the manufacturer in six colours with three of them corresponding to LGI and the remaining three to HGI. Each colour was assigned to one child to avoid mix up of the product packets among the toddlers at the centre. At any one time, only six toddlers (three for each product) were administered with the products. Thus, the researchers, the parents or the care takers at the day care centres were not aware of the type of test product being provided to the toddlers. The researchers carried equal numbers of the coloured test product packets to each of the centres to ensure appropriate randomisation of the milk products. A random number generator on a computer was used to randomise the toddlers.

Parents were interviewed to gather demographic and socioeconomic background characteristics of the toddlers, including the occupation of the parents. A questionnaire was used to collect information on the complementary feeding practices of the toddlers. The questions asked were as follows: type of food and beverages consumed, amount of food and the age at which the foods were introduced.

\section{Subjects}

The study population was intended to include toddlers in the age range of $18 \pm 3$ months. Toddlers were included in the study if the following criteria were met: (1) age range of $18 \pm 3$ months, (2) free from any disease condition, (3) absence of lactose intolerance, (4) should be able to replace any other milk consumed with the test milk, and (5) toddlers with no known underlying health complications. Breast-fed toddlers were also included in the study if they were breast fed only at night. The mothers reported that the toddlers were breast fed only during the night to gradually wean from breast feeding. It was considered unethical to completely stop the toddlers from breast feeding. However, toddlers with continued breast feeding throughout the study period were excluded.

Seventy-five parents gave a verbal consent to enrol their toddlers into the study. However, only 56 (74.6\%) parents signed up for the study. Thus, 56 toddlers were recruited for the study. Though we targeted the toddlers in the age range of $18 \pm 3$ months, the final age of enrolled toddlers were in the range of 14-24 months. The toddlers were recruited from different licenced day care centres in the federal territory of Kuala Lumpur and Putrajaya. The flow of the recruitment process is presented according to the Consolidated Standards of Reporting Trials (CONSORT) in Fig. 1.

\section{Test products}

Milk with differing GI values ("Low $=23$ " and "High = 65 ") comprised the test products. The nutrient composition of the test products is presented in Table 1. The test products are suitable for consumption by children (aged 1 year and above), and are currently available in the market. These products have been tested for glycaemic properties (low and high) in an independent accredited laboratory at the University of Sydney, Australia. Both products have passed through proper quality assurance procedures to ensure both are safe for consumption. The LGI product had a GI score of 23 and GL of 3, while the HGI product had a GI score of 65 and GL of 19. The milk formulas were isocaloric at about 29-32 kcals per scoop of $7 \mathrm{~g}$ of the test products. The main difference between the two products was that the HGI milk product contained added sugars contributing to a higher level of total CHO (71.7 \%), while the LGI milk product had no added sugars. The total $\mathrm{CHO}$ of the LGI product was close to regular fresh milk (38.8\%), thereby contributing to a lower GI value.

The toddlers were given the milk product 3 times a day at the day care centres. The composition of the administered test product was 4 scoops milk powder in $180 \mathrm{~mL}$ of water. The scoops were provided by the manufacturer. Each scoop of the milk product weighed $7 \mathrm{~g}$. The parents were also provided with an extra packet of the same milk powder to be consumed by the toddler at home. This was to ensure that no other milk would be provided to the child beyond the day care hours. The timing of the test feed was controlled at the day care centres. However, the test feed, if provided at home, was not controlled for timing, but there was reported compliance with the serving size.

\section{Anthropometry}

The children were weighed with minimum clothing to the nearest $10 \mathrm{~g}$ on a mechanical 2-16 kg capacity baby scale (Seca). The recumbent length (of children up to 2 years) or the standing height (of children 2 years and above) was measured to the nearest $\mathrm{mm}$. The measurements were standardised according to the WHO recommended method [36]. Special care was taken to determine the children's age with accuracy from the day care centres' records. The BMI-for-age, height-for-age and weight-forheight indices expressed in Z-scores were computed using the 1978 National Center for Health Statistics/WHO reference using Epinut software (Epi Info Version 6, Centers for Disease Control) [37].

Feeding practices were assessed through a qualitative 24-h recall, which was reported by the mothers. The food consumed by the toddlers in the day care centres was recorded by the researcher for the 3 days of the test period. 


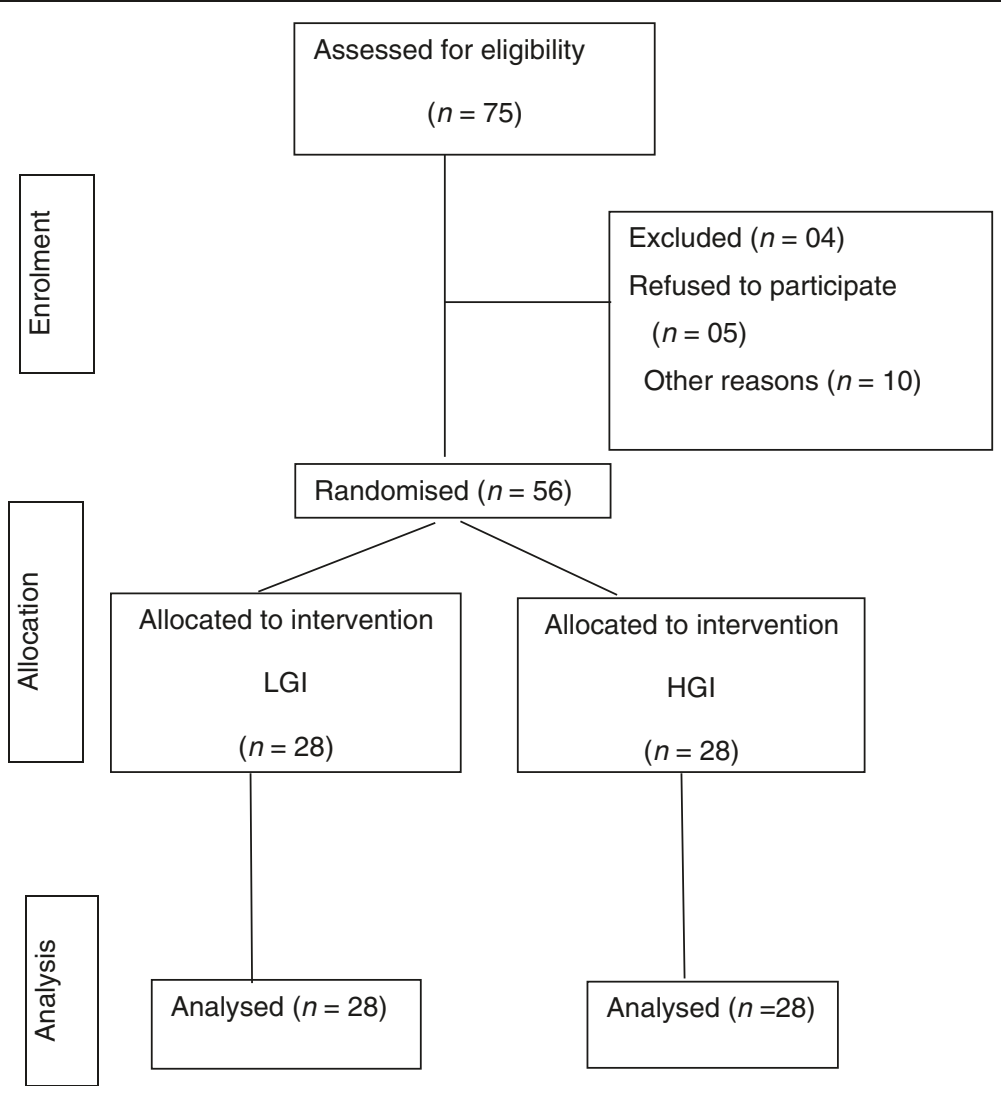

Fig. 1 Consolidated Standards of Reporting Trials (CONSORT) diagram for the flow of enrolment of the toddlers. LGI and HGI respectively represent the groups administered a low or high glycaemic index milk product

\section{Determination of sleep patterns}

Objective sleep assessment using actigraphy to determine sleep patterns was captured using the Philips Actiwatch 2, (Philips Healthcare, Andover, MD, USA). The Actiwatch device uses an accelerometer to detect and $\log$ wrist movement. Actigraphy has been shown to be a useful means for discriminating sleep from wake

Table 1 Nutrient composition of the test products

\begin{tabular}{lllll}
\hline Nutrients & LGl (23) & & HGl (65) & \\
& per 100 g & $\begin{array}{l}\text { per scoop } \\
(7 \mathrm{~g})\end{array}$ & per $100 \mathrm{~g}$ & $\begin{array}{l}\text { per scoop } \\
(7 \mathrm{~g})\end{array}$ \\
\hline Energy (Kcals) & 462 & 29 & 421 & 32 \\
Proteins (g) & 24.5 & 1.72 & 10.5 & 0.74 \\
Fat (g) & 22.2 & 1.55 & 11.3 & 0.79 \\
CHO (g) & 38.9 & 2.72 & 71.7 & 5.02 \\
Vit A(mcg) & 390 & 27.3 & 264 & 18.48 \\
Vit D (mcg) & 6.1 & 0.43 & 3.1 & 0.22 \\
Calcium (mg) & 830 & 58.1 & 355 & 24.9 \\
Iron(mg) & 11.4 & 0.79 & 5.5 & 0.39 \\
Zinc (mg) & 11.4 & 0.79 & 2.7 & 0.19 \\
\hline
\end{tabular}

Legends: $L G$ low glycaemic index, $\mathrm{HGI}$ high glycaemic index, $\mathrm{CHO}$ carbohydrate activity. Actigraphy assesses sleep in a naturalistic environment. Although actigraphy does not provide data on sleep architecture, one advantage of this technique is that it is unobtrusive and allows for data collection over an extended period of time [38]. Actigraphy is a useful diagnostic tool that can be used to estimate sleep parameters with specialised algorithms in computer software programs. It has been well validated for the estimation of night-time sleep parameters across age groups [38]. Actigraphy was chosen over polysomnography as it captures both day and night-time sleep without restricting the child's freedom of movement. Moreover, it was easy to monitor the sleep during the day time at the child care centres and also at night at home. It was less burdensome on the child care providers as well as the parents. The toddlers seemed to be well adapted to wearing the actigraph watches.

The Actiwatch data indicated children's sleep and wake states. Unlike parental report measures, actigraphy does not rely on observable behaviour to determine sleep states. An actigraph will accurately record a child's state as awake when he or she is in a state of quiet wakefulness, whereas his or her parent would be likely to report that the child is asleep. The Actiwatch was worn on 
the wrist of the child on the day before the administration of the test products to familiarise the child with the watch. The Actiwatch was worn by the child for a period of 3 days. The parents were requested to monitor that the child did not remove the watch when at home. The watch was removed after the study period. The obtained information was analysed using Actiware software version 6.0. Actiware software quantifies important sleep statistics such as sleep time, sleep efficiency and wake after sleep onset based upon user defined or automatically determined rest intervals. These features are designed to simplify analysis of activity data for sleep.

Sleep variables included TST, WASO, SOL and SE. TST represented the total amount of sleep in minutes (computed in hours for the present study) from onset of sleep to onset of awakening. WASO referred to the time (minutes) spent awake after sleep onset had occurred. SOL was the time period measured from "lights out" or "bedtime" to the beginning of sleep, and SE was defined as the proportion of sleep in the period potentially filled by the ratio of total sleep time to time in bed as a percentage, where a SE less than $85 \%$ is considered to be indicative of sleep disturbance [39].

\section{Statistical analysis}

Descriptive statistics were performed to report the data as mean \pm S.D. Sociodemographic characteristics and sleep outcomes were compared among both groups using the $t$ test and chi-square test for continuous and categorical data, respectively. All statistical analyses were evaluated at a significance level of $5 \%$ (two-tailed) and were conducted using IBM software version 21.

\section{Results}

\section{Participants' profiles}

The participants were recruited from July 2012 to April 2013 from 9 day care centres in Klang Valley and Putrajaya. Of the 75 eligible families who agreed to participate in the study, only $56(74.6 \%)$ consented. Hence, a total of 56 toddlers (37.5 \% boys and $62.5 \%$ girls) participated in the study with a mean age of $19.9 \pm 4.3$ years. About $43.6 \%$ of the toddlers were in the age range of $14-18$ months, with $56.4 \%$ of them being in the age range of 19-24 months. The majority of the toddlers were girls $(62.5 \%)$ with most $(96.4 \%)$ of them belonging to Malay ethnicity. Only $3.6 \%$ of the toddlers belonged to other ethnicities. The majority of the toddlers' parents (mothers $57.1 \%$; fathers $37 \%$ ) were aged less than 30 years, with a mean age of $30.9 \pm$ 4.1 years for the mothers and $33.3 \pm 5.3$ years for the fathers (Table 2). Socioeconomic statuses of the families (Table 2) revealed that $34 \%$ of the families had a household monthly income of less than RM 4000 (USD 1333). The majority (58.3\%) of the toddlers had one to two siblings. Most (92.4 \%) of the toddlers who participated in the study had a normal birth weight (2500$4000 \mathrm{~g})$ [36].

\section{Anthropometric profiles}

The BMI for age (Table 3) of the toddlers found $74.5 \%$ being of normal weight, with $12.7 \%$ at risk of overweight, $5.5 \%$ overweight and $7.3 \%$ underweight.

\section{Feeding practices during the study period}

All of the licensed day care centres followed a recommended menu of the $\mathrm{MOH}$, Malaysia. The meals provided to the toddlers at the day care centres could not be controlled for isocaloric standards. The study did not control for the meals provided at home. The total amount of the test feed consumed by each toddler per day ranged from 540 to $720 \mathrm{~mL}$ with $180 \mathrm{~mL}$ per feeding.

\section{Sleep characteristics}

The mean TST of the LGI and the HGI groups were $6.91 \pm 1.51$ and $6.90 \pm 1.64 \mathrm{~h}$, respectively (Table 4). The SOL for both groups was $13.27 \pm 7.97$ (LGI) and $13.07 \pm$ 9.38 (HGI) min. However, there were no significant differences between groups with respect to TST, SOL, WASO and SE.

\section{Discussion}

Cross-sectional and epidemiologic studies have demonstrated connections between sleep duration and diet. Many studies have indicated that an unhealthy diet is associated with shorter sleep duration and irregular sleeping patterns, despite differences in study methodology [38]. However, these studies have not reported on the quality of the macronutrients and the impact on sleep, especially among toddlers. $\mathrm{CHO}$ plays an important role in modulating sleep patterns, which is evident from many studies on adults and school children. However, studies on sleep patterns of toddlers consuming foods with different $\mathrm{CHO}$ quality have not been conducted [35].

The present study is possibly the first to test the shortterm impact of milk with differing GI amongst toddlers. This pilot study was carried out among 56 toddlers with a mean age of $19.9 \pm 4.3$ months, and was undertaken to evaluate the short-term impact of LGI and HGI test products on the sleep patterns of toddlers. No significant differences in the sleep patterns of toddlers consuming milk with differing GI values was observed. A possible explanation of this effect could be the short duration of the milk administration. If the study period would have been over a longer duration, the results may possibly have been different. Additionally, the complementary foods consumed by the toddlers were not controlled. Moreover, some of the toddlers were breast fed during the night. Given that the GI of breast milk is similar to 
Table 2 Sociodemographic profile of the subjects

\begin{tabular}{|c|c|c|c|}
\hline Characteristics $(n=56)$ & $\mathrm{LGI} n(\%)$ & $\mathrm{HGl} n(\%)$ & Total $n(\%)$ \\
\hline \multicolumn{4}{|l|}{ Age (months) } \\
\hline $14-18$ & 11 (39.3) & $14(51.9)$ & 24 (43.6) \\
\hline 19-24 & $17(60.7)$ & $13(48.1)$ & $31(56.4)$ \\
\hline Mean \pm S.D. & $20.46 \pm 3.8$ & $19.30 \pm 4.7$ & 19. $9 \pm 4.3$ \\
\hline \multicolumn{4}{|l|}{ Sex } \\
\hline Male & $10(34.5)$ & $11(40.7)$ & $21(37.5)$ \\
\hline Female & 19 (65.5) & $16(59.3)$ & $35(62.5)$ \\
\hline \multicolumn{4}{|l|}{ Ethnicity } \\
\hline Malay & $27(96.4)$ & 27(96.4) & $54(96.4)$ \\
\hline Others & $1(3.6)$ & $1(3.6)$ & $2(3.6)$ \\
\hline \multicolumn{4}{|l|}{ Mother's age (years) $(n=47)$} \\
\hline$\leq 30$ & $18(62.1)$ & $14(51.9)$ & $32(57.1)$ \\
\hline $31-35$ & $7(24.2)$ & $8(29.6)$ & $15(26.8)$ \\
\hline Mean \pm S.D. & $30.5 \pm 4.1$ & $31.30 \pm 4.3$ & $30.9 \pm 4.1$ \\
\hline \multicolumn{4}{|l|}{ Father's age (years) $(n=54)$} \\
\hline$\leq 30$ & $8(29.6)$ & $12(44.5)$ & $20(37.0)$ \\
\hline $31-35$ & $12(44.5)$ & $5(18.5)$ & $17(31.5)$ \\
\hline$>36$ & $7(25.9)$ & $10(37.0)$ & $17(31.5)$ \\
\hline Mean \pm S.D. & $32.8 \pm 4.4$ & $33.8 \pm 6.1$ & $33.3 \pm 5.3$ \\
\hline \multicolumn{4}{|l|}{ Mother's education $(n=56)$} \\
\hline Secondary & $9(31.0)$ & $5(18.5)$ & $14(25.0)$ \\
\hline College/University & $20(69.0)$ & $22(81.5)$ & $42(75.0)$ \\
\hline \multicolumn{4}{|l|}{ Father's education $(n=54)$} \\
\hline Secondary & $7(25.9)$ & $4(14.8)$ & $11(20.4)$ \\
\hline College/University & $20(74.1)$ & $23(85.2)$ & $43(79.6)$ \\
\hline \multicolumn{4}{|l|}{ Mother's occupation [53] $(n=55)$} \\
\hline Managers and professionals & $4(13.8)$ & $10(38.4)$ & $14(25.4)$ \\
\hline $\begin{array}{l}\text { Technicians/Associate } \\
\text { professionals }\end{array}$ & $14(48.3)$ & $6(23.2)$ & $20(36.4)$ \\
\hline Clerical support workers & $10(34.5)$ & $8(30.8)$ & $18(32.7)$ \\
\hline Service and sales workers & $0(0.0)$ & $1(3.8)$ & $1(1.8)$ \\
\hline Business owner & $1(3.4)$ & $1(3.8)$ & $2(3.7)$ \\
\hline \multicolumn{4}{|l|}{ Father's occupation [53] $(n=52)$} \\
\hline Managers and professionals & $7(25.9)$ & $6(24.0)$ & $13(25.0)$ \\
\hline $\begin{array}{l}\text { Technicians and associate } \\
\text { professionals }\end{array}$ & $11(40.8)$ & $13(52.0)$ & $24(46.1)$ \\
\hline Clerical support workers & $2(7.4)$ & $1(4.0)$ & $3(5.8)$ \\
\hline Service and sales workers & $3(11.1)$ & $0(0.0)$ & $3(5.8)$ \\
\hline $\begin{array}{l}\text { Plant and machine operators } \\
\text { and Assemblers/ Elementary } \\
\text { occupations }\end{array}$ & $2(7.4)$ & $2(8.0)$ & $4(7.7)$ \\
\hline Business owner & $2(7.4)$ & $3(12.0)$ & $5(9.6)$ \\
\hline \multicolumn{4}{|c|}{ Household monthly income $(n=56)$} \\
\hline$<4000$ & $12(41.4)$ & $7(26.0)$ & $19(34.0)$ \\
\hline RM4000 - 5999 & $7(24.1)$ & $9(33.3)$ & $16(28.6)$ \\
\hline
\end{tabular}

Table 2 Sociodemographic profile of the subjects (Continued)

\begin{tabular}{llll}
\hline RM6000 - 7999 & $7(24.1)$ & $7(25.9)$ & $14(25.0)$ \\
$\geq$ RM8000 & $3(10.4)$ & $4(14.8)$ & $7(12.4)$ \\
Number of siblings $(n=55)$ & & & \\
No siblings & $1(3.4)$ & $1(3.8)$ & $2(3.6)$ \\
$1-2$ & $15(51.7)$ & $17(65.4)$ & $32(58.3)$ \\
$3-4$ & $11(37.9)$ & $8(30.8)$ & $19(34.5)$ \\
$\geq 5$ & $2(6.9)$ & $0(0.0)$ & $2(3.6)$ \\
Child's Birth Weight $(\mathrm{kg})(n=53)$ & & & \\
Low birth weight $[37](<2.5)$ & $1(3.4)$ & $2(8.3)$ & $3(5.7)$ \\
Normal birth weight $(2.5-3.99)$ & $27(93.2)$ & $22(91.7)$ & $49(92.4)$ \\
High birth weight $(\geq 4.00)$ & $1(3.4)$ & $0(0.0)$ & $1(1.9)$ \\
Mean \pm S.D. & $3.1 \pm 0.4$ & $3.00 \pm 0.5$ & $3.1 \pm 0.4$
\end{tabular}

MASCO [53], Principles of Classification of Occupations (3rd Ed.). Putrajaya: Ministry of Human Resources

UNICEF and WHO [36]

Table 3 BMI for age, height for age, weight for age, and weight for height classifications for LGI and HGl groups

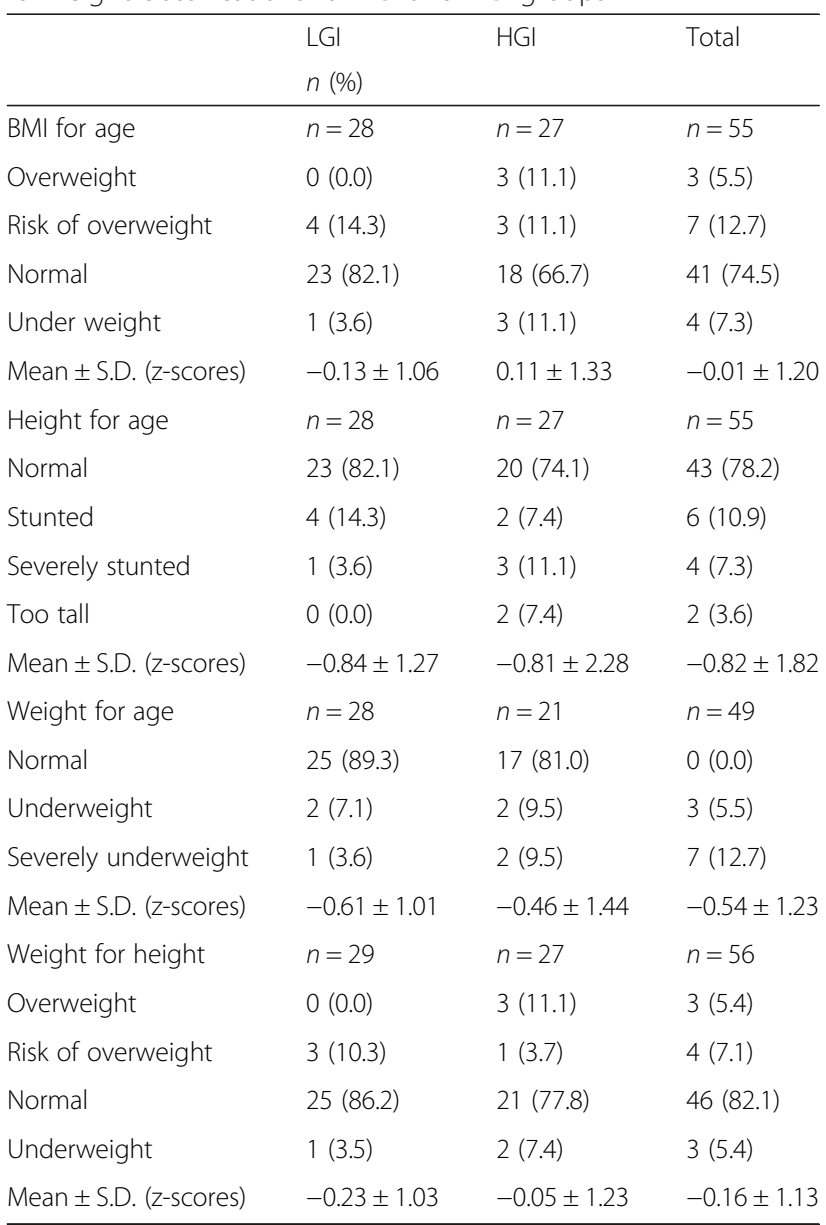


Table 4 Sleep patterns

\begin{tabular}{|c|c|c|c|c|}
\hline Test parameters & Measures & $\mathrm{HGl}(n=28)$ & LGI $(n=28)$ & $p$ value \\
\hline \multirow[t]{3}{*}{ Total sleep (hours) } & Mean \pm SD & $6.90 \pm 1.64$ & $6.91 \pm 1.51$ & 0.560 \\
\hline & Median & 6.58 & 7.09 & \\
\hline & Interquartile range & 1.22 & 1.15 & \\
\hline \multirow[t]{3}{*}{ Sleep Onset Latency (SOL)(minutes) } & Mean \pm SD & $13.07 \pm 9.38$ & $13.27 \pm 7.97$ & 0.724 \\
\hline & Median & 13.06 & 12.2 & \\
\hline & Interquartile range & 11.31 & 14.54 & \\
\hline \multirow[t]{3}{*}{ Wake after sleep onset (WASO) (minutes) } & Mean + SD & $13.29 \pm 10.25$ & $16.41 \pm 9.38$ & 0.158 \\
\hline & Median & 9.56 & 17.25 & \\
\hline & Interquartile range & 8.94 & 15.56 & \\
\hline \multirow[t]{3}{*}{ Sleep efficiency (\%) } & Mean \pm SD & $86.84 \pm 5.89$ & $88.29 \pm 5.01$ & 0.442 \\
\hline & Median & 87.34 & 89.05 & \\
\hline & Interquartile range & 7.51 & 6.49 & \\
\hline
\end{tabular}

(Significance level at $p<0.05$ )

that of the LGI test product, the difference of the impact of LGI could not be observed. However, the study demonstrates a slightly better trend in the sleep characteristics among the LGI group as compared with the HGI. Similar results were also reported by a study conducted among eight children (age 8-12 years) of both sexes; the mean SOL, rapid eye movement (REM) latency, TST and TWT were not significantly different in the LGI and HGI groups [40]. A study among toddlers reported that intake of $\mathrm{CHO}$ was accompanied by longer sleep duration $(0.8 \mathrm{~min} / \mathrm{g})$ [35]. However, this study did not examine the GI of the CHO. It was reported that HGI induces an increased sleep duration.

Dietary $\mathrm{CHO}$ contain a large variety of sugar chains with different metabolisms. Thus, it is not surprising that the amount of any individual $\mathrm{CHO}$ has no consistent influence on sleep parameters. A cross-sectional study on toddlers reported that the consumption of foods with high GI was accompanied by longer sleep time $(1.3 \mathrm{~min} / \mathrm{g})$ [35]. However, this result seems to be inconsistent with our study, possibly because of the short duration of test feed consumption. Another study among 12 healthy young men with normal weights reported that SOL was significantly different between the LGI and HGI meals given $4 \mathrm{~h}$ before bedtime and between the HGI meals given $4 \mathrm{~h}$ and $1 \mathrm{~h}$ before bedtime [41]. A study of a low$\mathrm{CHO}$ diet on sleep behaviours among six healthy female individuals showed no significant change in sleep time [42]. However, neither a high- nor low-CHO diet affected the sleep parameters.

The toddler and preschool years are generally considered the most difficult phase of life to study because toddler performance is influenced by factors that are outside of experimental control such as emotional state, motivation, persistence and comprehension of instructions. Thus, less research has been done in the toddler years not only because of this age-related variability, but also because there has been a greater emphasis on measures of overall cognitive development such as "IQ", which is notably difficult to assess until elementary school years [43-45].

A cross-sectional study among toddlers showed that the consumption of foods with a high GI was accompanied by longer sleep time $(1.3 \mathrm{~min} / \mathrm{g})[35,46]$. This may be because macronutrients stimulate the secretion of cholecystokinin, which has been reported to induce sleepiness $[35,44]$. However, in a clinical trial of 12 healthy young men consuming $\mathrm{CHO}$ meals with high or low GLs, profiling the type of $\mathrm{CHO}$ ingested did not affect sleep duration or any other sleep indexes according to polysomnographic recordings, except for the onset of sleep [39]. From the same study, it was observed that shortened SOL by approximately $10 \mathrm{~min}$ after a CHO-rich evening meal with a HGI compared with a LGI meal suggested a difference between the CHOs. The $\mathrm{CHO}$ content of these rice-based meals was more than $90 \%$ of the total energy content, and the meals were ingested $4 \mathrm{~h}$ before bedtime [39].

According to recent studies, HGI CHOs have the ability to increase the ratio of circulating Trp to LNAAs (Trp:LNAA) via a direct action of insulin, which promotes the selective muscle uptake of LNAAs [47]. The mechanism by which an HGI CHO meal shortens SOL is currently unknown. A possible mechanism may be that an HGI meal works through an increased plasma concentration of insulin and Trp to a large neutral amino acid ratio (Trp:LNAA) and its ability to compete for entry into the brain with other LNAAs. The entry of Trp into the brain is linked to its concentration relative to other LNAAs and the main determinant of brain serotonin concentration is a high plasma Trp:LNAA [17]. It is now 
known that the plasma Trp:LNAA is affected by dietary $\mathrm{CHO}$ and protein $[21,46]$.

In another study by Afaghi et al. [39] conducted among adults, a standard isocaloric meal $(3212 \mathrm{~kJ} ; 8 \%$ of energy as protein, $1.6 \%$ of energy as fat, and $90.4 \%$ of energy as $\mathrm{CHO}$ ) was provided to the study subjects with a GL of 81.3 and 175 for the LGI and HGI meals, respectively [39]. This enabled the standardisation of the meals for both the groups. However, in the present study, given that the subjects' belonged to different day care centres, it was not possible to standardise the meals. Though the day care centres followed the menu instructions provided by the $\mathrm{MOH}$, there could have been differences in the preparation methods and the ingredients mix. The caretakers of the day care centres reported that they would also make suitable changes if they found that the meals provided were not palatable to the toddlers. However, this was also not standardised across the recruited day care centres. Moreover, the food consumed at home was also beyond the control of the researchers. The macronutrient content of the meals may have obscured the impact of the test products.

An HGI meal resulted in a significant $(P=0.009)$ shortening of SOL in healthy sleepers compared with an LGI meal [35]. A study of a low-CHO diet on sleep behaviours in six healthy female individuals showed no significant changes in sleep time [48]. Mindell's study on cross-cultural differences in infant and toddler sleep reported that predominantly Asian countries had significantly later bed times and shorter TSTs [49]. The timing $[46,49,50]$ of the HGI [41] meal also affects sleep onset. An HGI meal ingested $4 \mathrm{~h}$ before bedtime was more effective in shortening the SOL than was the same meal ingested $1 \mathrm{~h}$ before bedtime [48].

Another study among toddlers reported that higher energy intakes with the evening meal were associated with a longer sleep duration $(1 \mathrm{~min} / 10 \mathrm{kcal}, p<0.01)$. With respect to absolute intakes, carbohydrates $(0.8 \mathrm{~min} / \mathrm{g}$, $p<0.0001)$, especially from HGI foods $(1.3 \mathrm{~min} / \mathrm{g}, p<0.01)$ and a higher GL $(1.5 \mathrm{~min} / \mathrm{g} \mathrm{GL}, p<0.01)$ were accompanied by longer sleeping time [49]. A meal consumed close to bedtime is associated with sleep disturbance [46]. Macronutrients [50-52] influence sleep through Trp, which serves as a precursor for brain serotonin, a sleep-inducing agent [49].

Further studies are suggested with a larger population to confirm the trends found in the present study. The non-significant results between the groups may also be attributed to the fact that the test products were administered for a very short time. Some of the toddlers continued breast feeding (at night only), which may also have interfered with the effect of the test products. Given that the GI of breast milk is very low, this may have overshadowed the effects of the test products.

\section{Conclusions}

In the present study, the sleep patterns of toddlers administered milk with a LGI did not differ from those consuming HGI milk formulations. This further strengthens the fact that there is no need to have any added sugars used for the GUM to improve the sleep patterns of this age group. The LGI formulations are preferable as these tend to be higher in dietary fibre and low in refined sugars and starches. Hence, a LGI GUM may be favourably used for this segment of the population, which would also prevent the child from the burden of over nutrition during their later years, thereby potentially reducing the pandemic of obesity. Future studies should consider the glycaemic effects of other foods, along with milk with differing GI, consumed for a longer feeding duration.

Study limitations include the small sample size and a lack of generalizability to other groups. The parents at the day care centres insisted on revealing the product identity. As the present study was double blinded, the protocol did not approve of divulging the product name. This was unacceptable to the parents, who therefore dropped out of the study. Given that mothers in the urban areas are generally well informed, they continued to breast feed their children for longer durations. Thus, excluding the breast-fed toddlers was a bigger challenge. To overcome this challenge, we included the toddlers who were breast fed at night only. Moreover, the complementary foods provided at the day care centres and at home were not standardised. This may have impacted the performance of the test products. However, owing to the growing evidence on the effects of GI on sleep, further studies can be carried out amongst the same age group of non-breast-fed toddlers with standardisation of their complementary foods.

\section{Abbreviations \\ Trp: Tryptophan; LNAAs: Large neutral amino acids; Gl: Glycaemic index; GL: Glycaemic load; T2DM: Type 2 diabetes mellitus; Moh: Ministry of Health, Malaysia; DHA: Docosahexaenoic acid; GUM: Growing up milk; LGI: Low glycaemic index; HGl: High glycaemic index; WHO: World Health Organization; CHO: Carbohydrates; TST: Total sleep time; SE: Sleep efficiency; WASO: Wake after sleep onset; SOL: Sleep-onset latency; REM: Rapid eye movement; TWT: Total wake time.}

Competing interests

The authors declare that they have no competing interests.

\section{Authors' contributions}

GLK, SM, PM, DB and SH: conceptualised and designed the study. DB and PM: scientific advisor and co-designed the study. SM and GLK: carried out the study, collected and analysed the data. SM, GLK, PM and SH: interpreted the data. SM and GLK: drafted the manuscript. PM, DB and SH: participated in the revision of the manuscript. All authors read and approved the final manuscript.

\section{Acknowledgements}

The authors thank the families who participated in the study and also the personnel at the day care centres. We are grateful to the research assistants, Ms. Sarina Sariman, Ms. Evelyn Soong and Ms. Grace Wong for their help in convincing the day care centres as well as the parents to enrol in the study. 


\section{Disclosure statement}

This research was funded by Fonterra Co-operative Group Limited. We have no financial conflicts of interest.

\section{Author details}

${ }^{1}$ Division of Nutrition and Dietetics, International Medical University, 57000 Kuala Lumpur, Malaysia. ${ }^{2}$ Department of Psychology, University of Nottingham, Malaysia Campus, 43500 Semenyih, Selangor Darul Ehsan, Malaysia. ${ }^{3}$ Department of Psychology, Monash University, Sunway Campus, 47500 Subang Jaya, Selangor, Malaysia. ${ }^{4}$ Department of Psychology, University of Swansea, Swansea SA2 8PP Wales, UK.

\section{Received: 3 February 2015 Accepted: 24 June 2015}

\section{Published online: 15 July 2015}

\section{References}

1. Carskadon MA, Dement WC. Normal Human Sleep: An Overview. In: Kryger MH, Roth T, Dement WC, editors. Principles and Practice of Sleep Medicine. 4th ed. Philadelphia: Elsevier Saunders; 2005. p. 13-23.

2. Thoman EB. Sleeping and waking states in infants: a functional perspective Neurosci Biobehav Rev. 1990;14:93-107.

3. Grigg-Damberger M, Gozal D, Marcus CL, Quan SF, Rosen CL, Chervin RD, et al. The visual scoring of sleep and arousal in infants and children. J Clin Sleep Med. 2007:3:201-40.

4. Parmelee AH, Stern E. Development of States in Infants. In: Clemente CD, Purpura DP, Mayer FE, editors. Sleep and the Maturing Nervous System. New York: Academic; 1972. p. 199-228.

5. Coons S, Guilleminault C. Development of sleep-wake patterns and non-rapid eye movement sleep stages during the first six months of life in normal infants. Pediatrics. 1982;69:793-8.

6. Iber C, Ancoli-Israel S, Chesson A, Quan SF. The AASM Manual for the Scoring of Sleep and Associated Events: Rules, Terminology and Technical Specifications. Westchester, IL: American Academy of Sleep Medicine; 2007.

7. Dollander M. Etiology of adult insomnia. Encephale. 2002;28:493-502

8. Tae Won K, Jong-Hyun J, Seung-Chul H. The impact of sleep and circadian disturbance on hormones and metabolism. Int J Endocrinol. 2015. doi:10.1155/2015/591729.

9. Pietrowsky R, Meyrer R, Kern W, Born J, Fehm HL. Effects of diurnal sleep on secretion of cortisol, luteinizing hormone, and growth hormone in man. Journal of Clinical Endocrinology and Metabolism. 1994;78(3):683-7.

10. Weibel L, Follenius M, Spiegel K, Gronfier C, Brandenberger G. Growth hormone secretion in night workers. Chronobiology International. 1997;14(1):49-60.

11. Van Cauter E, Kerkhofs M, Caufriez A, Van Onderbergen A, Thorner MO, Copinschi G. A quantitative estimation of growth hormone secretion in normal man: reproducibility and relation to sleep and time of day. Journal of Clinical Endocrinology and Metabolism. 1992;74(6):1441-50.

12. Roky R, Chapotot F, Hakkout F, Benchekroun MT, Buguet A. Sleep during Ramadan intermittent fasting. J Sleep Res. 2001;10:319-27.

13. Porter JM, Horn JA. Bed-time food supplement and sleep: effect of different carbohydrate levels. Electromyogr Clin Neurophysiol. 1981:51:426-33.

14. Wells AS, Read NW, Uvnas-Moberg K, Alster P. Influences of fat and carbohydrate on postprandial sleepiness, mood, and hormones. Physiol Behav. 1997;61:679-86.

15. Hartmann E, Spinweber CL. Sleep induced by L-tryptophan: effect of dosages within the normal dietary intake. J Nerv Ment Dis. 1979;167:497-9.

16. Hartmann E. Effect of L-Tryptophan on sleepiness and on sleep. J Psychiatr Res. 1982/83;17:107-13.

17. Fernstron JD, Wurtman RJ. Brain serotonin content: physiological regulation by plasma neutral amino acids. Science. 1972;178:414-6.

18. Larsen TM, Dalskov SM, van Baak M, Jebb SA, Papadaki A, Pfeiffer AF, et al. Diets with high or low protein content and glycaemic index for weight-loss maintenance. N Engl J Med. 2010;363(22):2102-13.

19. Barclay A, Petocz P, McMillan-Price J, Flood V, Prvan T, Brand-Miller J. Glycaemic index, glycaemic load and chronic disease risk: a meta-analysis. American Journal of Clinical Nutrition. 2008:87:627-37.

20. Fernstrom JD. Tryptophan Availability and Serotonin Synthesis in Brain. In: Huether G, editor. NATO ASI Series, Vol H 20, Amino acid Availability and Brain Function in Health and Disease. Berlin: Springer-Verleg; 1988.
21. Wurtman RJ, Wurtman JJ, Regan MM, McDermott JM, Tasay RH, Breu JJ. Effect of normal meals rich in carbohydrates or proteins on plasma tryptophan and tyrosine ratios. Am J Clin Nutr. 2003;77:128-32.

22. De Onis M, Blossner M, Borghi E. Global prevalence and trends of overweight and obesity among pre-school children. Am J Clin Nutr. 2010;92(5):1257-64.

23. National Coordinating Committee on Food and Nutrition, Ministry of Health Malaysia. Malaysian Dietary Guidelines for Children and Adolescents. Putrajaya, Malaysia: MOH; 2013.

24. Khor GL, Shariff ZM, Sariman S, Huang SLM, Mohamad M, et al. Milk drinking patterns among Malaysian Urban children of different household income status. J Nutr Health Sci. 2014;1(4):403.

25. Brand-Miller J, Atkinson F, Rowan A. Effect of added carbohydrates on glycaemic and insulin responses to children's milk products. Nurients. 2013:5:23-31. doi:10.3390/nu5010023.

26. Willett W, Manson J, Liu S. Glycaemic index, glycaemic load, and risk of type 2 diabetes. Am J Clin Nutr. 2002:76 Suppl:274S-80S.

27. Laposky AD, Bass J, Kohsaka A, Turek FW. Sleep and circadian rhythms: key components in the regulation of energy metabolism. FEBS Lett. 2008;582:142-51

28. Van Cauter E, Spiegel K, Tasali E, Leproult R. Metabolic consequences of sleep and sleep loss. Sleep Med. 2008;9 Suppl 1:S23-8.

29. Crisp AH. Sleep, activity, nutrition and mood. Br J Psychiatry. 1980;137:1-7.

30. Waterhouse J, Minors D, Atkinson G, Benton D. Chronobiology and meal times: internal and external factors. Br J Nutr. 1997;77 Suppl 1:S29-38.

31. Yehuda S, Rabinovitz S, Mostofsky DI. Essential fatty acids and sleep: mini-review and hypothesis. Med Hypotheses. 1998;50:139-45.

32. García-García F, Drucker-Colín R. Nutritional impact on sleep-wake cycle. Nestle Nutr Workshop Ser Clin Perform Programme. 2001:5:189-97.

33. Roenneberg T, Kuehnle T, Juda M, Kantermann T, Allebrandt K, Gordijn M, et al. Epidemiology of the human circadian clock. Sleep Med Rev. 2007:11:429-38.

34. Peuhkuri K, Sihvola N, Korpela R. Diet promotes sleep duration and quality. Nutrition Research. 2012;32:309-19.

35. Diethelm K, Remer T, Jilani H, Kunz C, Buyken AE. Associations between the macronutrient composition of the evening meal and average daily sleep duration in early childhood. Clin Nutr. 2011;30:640-6.

36. UNICEF and WHO. United Nations Children's Fund and World Health Organization, Low Birth weight: Country, regional and global estimates. New York: UNICEF; 2004

37. Nancy MD, Rebecca FG, Andrea M, Juhani M, Noel CB. Comparison of the New World Health Organization growth standards and the National Center for Health Statistics growth reference regarding mortality of malnourished children treated in a 2006 Nutrition Program in Niger. Arch Pediatr Adolesc Med. 2009:163(2):126-30.

38. Jennifer LM, Alex DH. Wrist Actigraphy. Chest. 2011;139(6):1514-27. doi:10.1378/chest.10-1872

39. Afaghi A, O'Connor H, Chow CM. High-glycaemic-index carbohydrate meals shorten sleep onset. Am J Clin Nutr. 2007:85:426e30.

40. Jalilolghadr S, Afaghi A, O'Connor H, Chow CM. Effect of low and high glycaemic index drink on sleep pattern in Children. J Pak Med Assoc. 2011;61(6):533-6.

41. Laurent J, Catanzaro SJ, et al. A measure of positive and negative affect for children: scale development and preliminary validation. Psychological Assessment. 1999:11(3):326-38.

42. Kwan RM, Thomas S, Mir MA. Effects of a low carbohydrate isoenergetic diet on sleep behavior and pulmonary functions in healthy female adult humans. J Nutr. 1986;116:2393-402

43. National Coordinating Committee on Food and Nutrition, Malaysia (NCCFN). Recommended Nutrient Intakes. Malaysia: Institute of Medical Research, Ministry of Health; 2005.

44. Kranzler JH. Assessment of children and youth from culturally and linguistically diverse backgrounds with mental chronometric techniques. Percept Mot Skills. 1998;86:321-2 [PubMed].

45. Kranzler $\mathrm{JH}$. Educational policy issues related to the use and interpretation of intelligence tests in the schools. School Psyc Rev. 1997;26:150-63.

46. Canivez GL, Watkins MW. Long-term stability of the Wechsler intelligence scale for children. Third Edition. Psycholl Assess. 1998;10:285-91.

47. Berry EM, Growdon JH, Wurtman JJ, Caballero B, Wurtman RJ. A balanced carbohydrate: protein diet in the management of Parkinson's disease. Neurology. 1991;41:1295-7. 
48. Silber BY, Schmitt JA. Effects of tryptophan loading on human cognition, mood, and sleep. Neurosci Biobehav Rev. 2010:34:387e407.

49. Mindell JA, Sadeh A, Wiegand B, How TH, Goh DY. Cross-cultural differences in infant and toddler sleep. Sleep Med. 2010;11(3):274-80. doi:10.1016/j.sleep.2009.04.012.

50. Pierre JM, Igor Allaman. Brain Energy Metabolism. Neuroscience in the 21st Century. Springer Science and Business media; 2013.p 1591-1620.

51. Micha R, Rogers PJ, Nelson M. Glycaemic index and glycaemic load of breakfast predict cognitive function and mood in school children: a randomised controlled trial. Br J Nutr. 2011;106(10):1552-61. doi:10.1017/S0007114511002303.

52. Afaghi A, O'Connor $\mathrm{H}$, Chow CM. Acute effects of the very low carbohydrate diet on sleep indices. Nutr Neurosci. 2008;11:146e54

53. Malaysia Classification of Occupations (MASCO) 3rd Edition. Ministry of Human Resources, Putrajaya, Malaysia; 2008.

\section{Submit your next manuscript to BioMed Central and take full advantage of:}

- Convenient online submission

- Thorough peer review

- No space constraints or color figure charges

- Immediate publication on acceptance

- Inclusion in PubMed, CAS, Scopus and Google Scholar

- Research which is freely available for redistribution 